\title{
Artificial Feeding of Amblyomma cajennense (Fabricius, 1787) (Acari: Ixodidae) through Silicone Membrane
}

\section{Saulo Teixeira de Moura, Adivaldo Henrique da Fonseca $/{ }^{+}$, Claudia Gorgulho Nogueira Fernandes, Jerry F Butler*}

\begin{abstract}
Departamento de Epidemiologia e Saúde Pública, Universidade Federal Rural do Rio de Janeiro, Caixa Postal 74548, 23851-970 Seropédica, RJ, Brasil *Department of Entomology and Nematology, IFAS, University of Florida, Building 970, Hull Road, Gainesville FL 32611-0620, USA
\end{abstract}

An artificial feeding system was used where citrated bovine blood was offerred to male and female Amblyomma cajennense. Vestiges of blood, sweat, hair and exfoliated skin were used as phago-stimulants placed on the surface of the silicone membrane. The ticks were collected, as engorged nymphs, from naturally infested equines, with the ecdysis occurring in the laboratory. Four hundred ticks were used, $50 \%$ being female, at three to four weeks post-ecdysis. Vestiges of blood on the silicone membrane were the most efficient phago-stimulant and the association of vestiges of blood and sweat residue smears yielded better results compared to the other phago-stimulants used.

Key words: Amblyomma cajennense - silicone membranes - artificial feeding - equines

Artificial feeding of hematophagous arthropods was documented by Rodhaim et al. (1912), using defibrinated ovine blood and rat skin membrane to feed Glossina palpalis. Galun (1967) cited the existence of stimulants that regulate the feeding behavior of hematophagous arthropods, such as vision, temperature, relative humidity and chemical factors, that can act in combination or in isolation. Davis et al. (1983) described the preparation and use of a reinforced silicone membrane for the artificial feeding of Culicoides mississippensis. Stone et al. (1983) artifically fed Ixodes holocyclus using a silicone membrane. Butler et al. (1984) found five tick species of the Ornithodoros genus capable of being infected with the African Swine Fever using an artificial feeding system with silicone membrane.

The different feeding strategies employed by the hematophagous arthropods have determined various degrees of difficulty in the search for the establishment of efficient technologies for their laboratory feeding. The hard ticks stand out as the arthropods that present the greatest difficulties in the development of an artificial feeding system capable of attending their needs. According to

This work was supported by a grant from the Conselho Nacional de Desenvolvimento Científico e Tecnológico (CNPq), Brazil, and represents the first author's MSc. Thesis presented to the Universidade Federal Rural do Rio de Janeiro.

${ }^{+}$Corresponding author. Fax: +55-21-682.1109

Received 19 April 1996

Accepted 12 May 1997
Brown (1989), the feeding strategy of ticks involves the mechanical reaction of their buccal appendages, effective in secreting substances like the prostaglandin E2 and anti-histamines, in the formation of a dermal pool where they feed. The same author showed that the argasid ticks differed from the ixodid ticks by the way they nourish themselves on the hosts and determined reactions which differed between these two tick Families. Because of this, the artificial feeding of the ixodids is more difficult, due to the necessities of greater attachment time and the necessary combination of host reactions required to meet their feeding needs.

The objective of this study was to determine the effectiveness of different phago-stimulants collected from the hosts in initiating the attachment and feeding of $A$. cajennense in the laboratory utilizing silicone membrane and citrated bovine blood.

\section{MATERIALS AND METHODS}

The specimens of A. cajennense used were collected from equines belonging to the Farm of the Instituto de Zootecnia, Universidade Federal Rural do Rio de Janeiro, municipality of Seropédica, State of Rio de Janeiro. The ixodids ticks were obtained, as engorged nymphs, from the animals and maintained in a bioclimatized chamber at $28 \pm 1^{\circ} \mathrm{C}$ and $75 \%$ relative humidity (RH) until adulthood.

For the contention of the ticks, cages of $120 \mathrm{cc}$ disposable plastic containers were constructed. For better air circulation, each cage contained three rectangular openings protected by tulle and covered with metal mesh. The bottom was substituted by silicone membrane, with a mean tickness of $0.056 \mathrm{~mm}$. 
The feeding system was based on the utilization of silicone membranes and an electrically heated plate (Davis et al. 1983). Blood was asseptically collected from the jugular vein of donor cows or calves into $10 \mathrm{ml}$ Vacutainer blood collection tubes containing $0.07 \mathrm{ml}$ of $10 \%$ sodium citrate as the anticoagulant. During the feeding process, the cages were maintained in a chamber with a regulated internal temperature of $28 \pm 1^{\circ} \mathrm{C}$. The RH was $75 \% \pm 5 \%$ and the feeding surface was maintained at $37 \pm 1^{\circ} \mathrm{C}$.

Forty plastic cages with 10 adult specimens of A. cajennense in each, were used at three to four weeks of post-ecdysis; $50 \%$ of the ticks in each cage were female. The feeding chambers were filled with $3.5 \mathrm{ml}$ of pre-heated blood and changed every $8 \mathrm{hr}$. Feeding response was observed through a stereoscopic microscope. The cages with the ticks were maintained in such a way so as to allow ample surface contact between the silicone membrane and the blood.

Phago-stimulants utilized in isolation - Vestiges of blood, sweat and exfoliated skin collected from equines, naturally infested with $A$. cajennense were used. To treat the membranes with sweat or blood, approximately $3 \mu 1$ of these substances were spread on the surface of the membrane. Sweat was collected from the animal immediately prior to use. The hair and exfoliated skin were placed in contact with the membranes $48 \mathrm{hr}$ prior to use.

Phago-stimulants utilized in association - The association of blood and sweat; blood, hair and exfoliated skin; blood, sweat, hair and exfoliated skin; sweat, hair and exfoliated skin; and the control group without any type of treatment, were studied.
The sequence of the treatment of the membranes in respect to the type of association and the phago-stimulant used, was first with blood, secondly with sweat and ultimately with hair and exfoliated skin.

\section{RESULTS}

The final rate of the partially fed ticks obtained was $10.5 \%$ in 400 tested ticks. From the 42 partially fed specimens, $19(4.75 \%)$ were females and $23(4.75 \%)$ were males.

Phago-stimulants used in isolation - The ticks were attracted to the membrane with blood on the 3rd and 4th day of the experiment. On the 8th and 9th days of the test, the ixodids started to attach themselves and blood ingestion occurred in 18 specimens (Table). In the cages with sweat treated membrane, attachment occurred with five specimens. The attachment by the specimen occurred on the 8th and 9th day, and the blood uptake started on the 11th day. In the cages with membranes treated with hair and exfoliated equine skin and in the control group, there was no attachment.

Phago-stimulants used in combination - In all of the cages, tick initial behavior was to assemble themselves, and search the membrane surface. The combination of blood and sweat resulted in 12 partially fed ticks (Table), with the attachment starting on the 6th day. The association of blood, sweat, hair and exfoliated skin resulted in lower feeding and attachment rate with five ticks partially fed. In the cages with the membranes treated with blood, hair and exfoliated skin, two ticks attached on the 9th day and partially fed. In the cages with sweat, hair and exfoliated skin and in the control group, there was no attachment.

TABLE

Amblyomma cajennense fed with citrated bovine blood, with a temperature of $37 \pm 1^{\circ} \mathrm{C}$, through silicone membrane, utilizing different phago-stimulants

\begin{tabular}{|c|c|c|c|c|c|c|c|}
\hline \multirow{2}{*}{$\frac{\text { Phago-stimulants }}{\text { Blood vestiges }}$} & \multicolumn{2}{|c|}{ Fed ticks } & \multirow{2}{*}{$\frac{\%}{22.5}$} & \multirow{2}{*}{$\begin{array}{c}\text { Male } \\
9\end{array}$} & \multirow{2}{*}{$\begin{array}{l}\% \\
50\end{array}$} & \multirow{2}{*}{$\begin{array}{c}\text { Female } \\
9\end{array}$} & \multirow{2}{*}{$\begin{array}{l}\% \\
50\end{array}$} \\
\hline & 18 & (80) & & & & & \\
\hline Sweat residue & 5 & (60) & 8.3 & 2 & 40 & 3 & 60 \\
\hline Hairs and exfoliated skin & 0 & (60) & 0 & 0 & 0 & 0 & 0 \\
\hline Blood + sweat & 12 & (40) & 30 & 7 & 58 & 5 & 42 \\
\hline Blood + hair and exfoliated skin & 2 & (40) & 5 & 1 & 50 & 1 & 50 \\
\hline Blood + sweat + hairs and exfoliated skin & 5 & (40) & 12.5 & 4 & 80 & 1 & 20 \\
\hline Sweat + hair and exfoliated skin & 0 & (40) & 0 & 0 & 0 & 0 & 0 \\
\hline Control group & 0 & (40) & 0 & 0 & 0 & 0 & 0 \\
\hline Average & & & & 3 & & 2.75 & \\
\hline Standard deviation & & & & 3.54 & & 3.19 & \\
\hline Variance & & & & 12.57 & & 10.21 & \\
\hline
\end{tabular}

Numbers in parenthesis indicate the total ticks used. 


\section{DISCUSSION}

There was no significant difference in the percentages of male and female $A$. cajennense, artificially fed ( $p>0.05)$. Hokama et al. (1987) who worked with Ornithodoros coriaceus, obtained a higher feeding rate in females. Uchikawa (1976) affirmed that there was no difference in the proportion of artificially fed male and female Argas japonicus.

The membrane treated with vestiges of blood was shown to be more efficient when compared with other phago-stimulants. There was a rate of $5 \%$ of partially fed ticks when blood was combined with hair and exfoliated skin, while the isolated treatment of the membrane with hair and exfoliated skin was unsuccessful, confirming the phagostimulation of the blood. The variation of the fed ixodids by means of treated membrane with blood vestiges was between $5 \%$ and $30 \%$, in accordance with the employed treatment (Table).

The isolated treatment of membrane with sweat residue, also resulted in successful attachment of the ixodids, with a rate of $8.3 \%$ of partially fed specimens. The association of blood vestiges and sweat residue in the treatment of the silicone membranes, established a more rapid attachment of six days. The highest percentage of partially engorged ixodids was also obtained using this combination, making it the most efficient phago-stimulant. Blood and sweat, both being body fluids, possess similar components, like $\mathrm{Na}, \mathrm{K}$, chloride, lactate, glycoproteins, and nitrogens compound. The successful association of the blood and sweat as phagostimulants, may be explained by the various types of treatment studied in more detail by other authors (Galun 1967).

Hair and skin exfoliation, when used separately or in association with sweat residue, did not produce a phago-stimulant effect. The use of hair as phago-stimulants was cited by Butler et al. (1984) as not being necessary for ticks from the genus Ornithodoros to feed on the silicone membrane. However, Hokama et al. (1987), after testing various types of hair and artificial threads, concluded that the guinea pig hair influenced the feeding of these argasids. Waladde et al. (1991) affirmed that it was necessary to consider the need of the tactile stimulants for the attachement of the ixodids. In this case, cotton wool and rabbit hair were added to the Baudruche membrane.

The importance of the control of the blood temperature as a feeding stimulant for ticks was reported by Galun (1967). Waladde et al. (1991) confirmed that the rise and fall in temperature, with food available to the ticks caused the specimens immediate detachment. This was recorded in this study, especially during blood changes. The use of an electric heating plate, instead of a humid sourse to heat the blood (Butler et al. 1984), could have caused the low humidity on the feeding surface, making tick attachment more difficult.

Waladde et al. (1991) utilized whole defibrinated blood, as a source of nutrients for the ticks and developed a method capable of satisfying the needs of these arthropods for membrane attachment and feeding, in the absence of natural hosts. The authors used Ixodid's excretion and washings from the parasitized regions, obtaining good results as attachment stimulants. Waladde et al. (1993) utilized similar procedures, reported higher rates in engorged ticks with heparinized blood. The authors did not achieve complete engorgement in the ixodids with the use of the citrated blood or with EDTA.

Galun (1967) and Galun and Kindler (1968) reported that the $\mathrm{RH}$ is directly involved in almost all the stages of nutrition of hematophagous arthropods. Thus the manner in which the blood was heated, the atmosphere of the tests, the reposition of the blood and the intense handling of the cages, are aspects that need to be studied further, seeking more efficient alternatives for artificial feeding of A. cajennese.

\section{REFERENCES}

Brown SJ 1989. Pathological consequences of feeding by hematophagous arthropods: comparison of feeding strategies. Misc Publication Am Entomol Soc 71: 4-14.

Butler JF, Hess WR, Endris RG, Holcher KH 1984. In vitro feeding of Ornithodoros ticks for rearing and assessment of diseases transmission, p. 1075-1081. In DA Griffiths, CE Bowman (eds), Acarology VI, Vol 2. Ellis Horwood, West Sussex, England.

Davis EL, Butler JF, Roberts RH, Reinert JF, Kleine DL 1983. Laboratory blood feeding of Culicoides mississippensis (Diptera: Ceratopogonidae) through a reinforced membrane. J Med Entomol 20: 177182.

Galun R 1967. Feeding stimuli and artificial feeding. Bull WHO 36: 590-593.

Galun R, Kindler SH 1968. Chemical basis of feeding in the tick Ornithodoros tholozoni. J Insect Physiol 14: 1409 .

Hokama Y, Lane RS, Howarth JA 1987. Maintenance of adult and nymphal Ornithodoros coriaceus (Acari: Argasidae) by artificial feeding through a parafilm membrane. J Med Entomol 24: 319-323.

Rodhain J, Pons C, Vandenbranden J, Bequaert J 1912 Contribution au mecanisme de la transmission des tripanosomes par les glossines. Arch Schiffs-u Tropen-Hyg 16: 732-739.

Stone BF, Commins MA, Kemp DH 1983. Artificial feeding of the Australian paralysis tick Ixodes holocyclus and collection of paralysing toxin. Int J Parasitol 13: 447-454.

Uchikawa K 1976. A membrane feeding method for 
548 A. cajennense Fed with Cattle Blood through Silicone Membrane - ST Moura et al.

Argas japonicus (Ixodoidea: Argasidae) and applications of this method for culturing the tick and for oral infecting of japanese encephalitis virus. Jpn J Sanit Zool 27: 207- 216.

Waladde SM, Ochieng SA, Gichuhi PM 1991. Artificial membrane feeding of the ixodid tick, Rhipicephalus appendiculatus, to repletion. Exp Appl Acarol 11:
297-396

Waladde SM, Young AS, Ochieng SA, Mwaura SN, Mwakima FN 1993. Transmission of Theileria parva to cattle by Rhipicephalus appendiculatus adults fed as nymphae in vitro on infected blood through an artificial membrane. Parasitology 107: 249-256. 